\title{
Passive and active thermography application for architectural monuments
}

\author{
by B. Więcek * and M. Poksińska** \\ * Institute of Electronics, Technical University of Łódź, Poland \\ ** Nicholas Copernicus University, Institute of Conservation and Restoration of \\ Cultural Property, Poland
}

Abstract - This paper presents the results of the research in gothic churches using static and dynamic thermography. The main aim was to evaluate the actual state and authenticity of the monumental substance. The thermographic surveys confirmed by material composition tests, show the useness of new method applied for conservation of monuments.

\section{Introduction}

Since 70-ties last century, themography is successfully applicable for monuments conservation. Initially, it was used for pictorial painting and architectural monuments, mainly for microclimate parameter estimating including moisture of walls. The Italian researchers was playing a pioneer role in these works, showing the first results in Scrovegni chapel in Padova [1], and the wall moisture evaluation in the basilica on Torcello island [2].

Since that moment, the significant progress in thermographic techniques was observed [4-10]. The investigations presented in this paper were realized during 2003-2006 as the research project subsidized by Polish Ministry of Science. The research concerned the chosen gothic architecture in Poland, including evaluation of historical sources, estimation of actual state of the monuments, authenticity of the monumental substance and determining the techniques suitable for studies of paintings, frescos and plasters [3]. Variety of examples of XIV-century buildings are presented here, including 3 churches in Malbork, Kwidzyn and Torun. All of them were in use by Lady Mary friars, and Malbork was their first European residence.

\section{Static thermography}

Static (passive) thermography is based on temperature measurements with the use of the emissivity of the investigated objects. In some cases by knowing the temperature, the distribution of emissivity factor can be used for characterization the objects' surface. Passive infrared thermography operates in 2 wavelength ranges, i.e.: 3-5 $\mu \mathrm{m}$ (SWIR) and 8-12 $\mu \mathrm{m}$ (LWIR). Infrared (IR) radiation energy depends on the chosen wavelength range, and for low-temperature objects is much higher for the long wavelengths. As architecture monuments have almost ambient temperature, the LWIR IR equipment is recommended. In order to use IR techniques effectively, the following parameters should be taken in to account:

- state of the surface,

- material contents of the object,

- temperature,

- humidity,

- alive organisms such as bacteria and mushrooms,

- chemical and biological processes such as fermentation. 
Most of the architectural objects are consisting of multilayer structures. It denotes that due to the thermal phenomena, the internal layers can have an impact on the temperate distribution on the outer surface. It depends on the thickness and thermal properties of the first layer, as well as the thermal capacity of the layers inside. Dense, bulk materials can accumulate heat for a long time, what can be visible on the surface, even if it originates from the inside. In practice, the warmed object during the day can be thermally monitored by night. Such investigation can lead to determine e.g.: the thickness, age and material contents of the plaster.

The exemplary results of the investigation performed in Malbork Castle are presented in Fig 1. The investigations were done with the use of IR and visual radiation separated into 3 subbands $-R$ (red), $G$ (green), $B$ (blue). In order to perform the measurements, the computerized image processing system was realized together with University of Nicolas Copernicus in Torun and Technical University of Lodz (Fig. 6,7). This system is dedicated for IR investigations both for passive and active thermography in different spectral ranges. As an example shown in Fig. 1, the small architectural detail (in Polish: zacheuszek) is clearly visible in $\mathrm{B}(\mathrm{blue})$ range only.
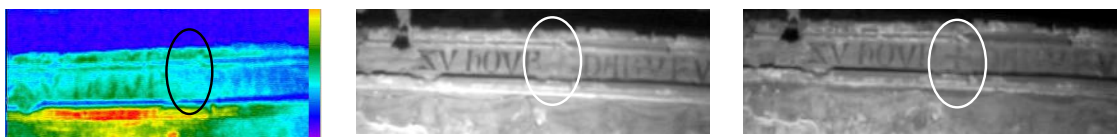

Fig. 1. Polychrome - IR 3-5 $\mu \mathrm{m}$ (left), IR1.2 $\mu \mathrm{m}$ (middle), visible blue B (right)

\section{Application of dynamic thermography for architecture monuments investigations}

Dynamic (active) thermography is a method where the energy is delivered into the object in the dynamic (periodic or single-shot) way. Heat penetrates the investigated body and the surface temperature distribution strongly depends on the thermal properties of the internal layers. High energy IR lamps can be used as energy sources, as shown in Fig. 6 and 7. With the aid of thermal modeling, it is possible to reconstruct the internal structure, sometimes full of defects, delaminations, different layers, etc.

Defects in the solid materials (cracks) can be easily modeled by introducing different local thermal properties into the investigated body, mainly as a low thermal conductivity. Because of the low thermal conductivity, thermal response on the front side of the solid varies, and it gets higher temperature after certain time from the beginning of pulse excitation. High-energy pulse is typically generated by flashing lamps. One-dimensional model of the heat transfer in the solid activated by the energy pulse $\mathrm{I}_{0}$, leads to the analytical solution presented by

$$
T(0, t)=\frac{I_{0}}{\sqrt{\pi \rho \lambda c_{p} t}}\left(1+2 \sum_{i=1}^{\infty} R^{i} e^{-\frac{i^{2} z^{2}}{a t}}\right),
$$

where $z$ is the depth of the crack. 


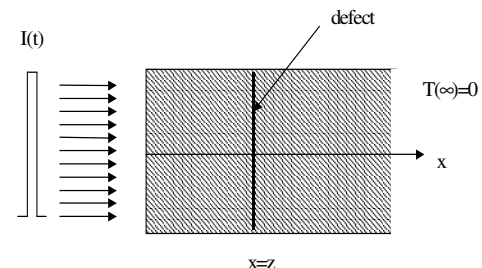

Fig. 2. Sample with the crack

It is very convenient to use reflection coefficient $R$, where $R \in<0,1>$, which takes a form

$$
R=\frac{e_{1}-e_{2}}{e_{1}+e_{2}}
$$

where: effusivities $e_{1}$ and $e_{2}$ depend upon the material constants for the solid and crack, respectively.

Effusivity can be expressed as $e=\left(\rho \lambda c_{p}\right)^{0.5}$. For vacuum $e_{2}=0$, and $R=1$, what makes the thermal response on the front side of the body the most visible. Thermal contrast $\mathrm{K}$ (egn. 3) is the next very useful parameter. It is defined as difference between temperature close the crack and one where the homogenous material is. Thermal contrast takes a form:

$$
K(t)=\frac{2 I_{0}}{\sqrt{\pi \rho \lambda c_{p}}} \sum_{i=1}^{\infty} R^{i} e^{-\frac{i^{2} z^{2}}{a t}} .
$$

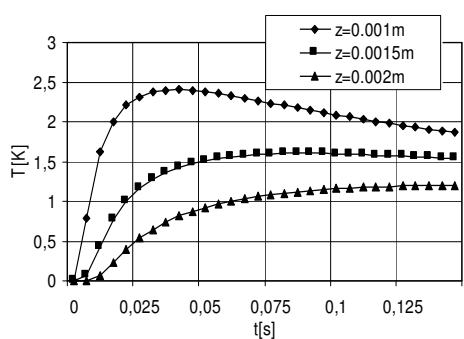

Fig. 3. Crack depth influence on thermal contrast

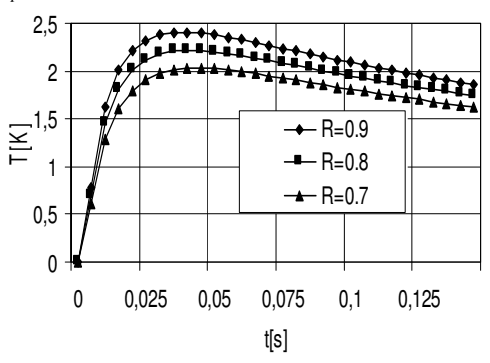

Fig. 4. Reflection coefficient influence on thermal contrast

Temperature contrast versus time for different depth of the crack is presented in Fig. 3 and 4. As illustrated, the thermal contrast depends on time, and it gets maximum value, which depends on the defect depth. Thermal parameters of the crack have an influence on the thermal contrast - maximum appears for almost the same time after excitation for different R (Fig.4). It is noticeable, that the higher $\mathrm{R}$ gives higher thermal contrast.

Thin film parameters evaluation is one of the possible and demanded applications of thermography for NDT (Non Destructive Testing). By using pulse or lock-in thermography, one can measure e.g. the thickness of the thin film coating or rusted areas, mainly in invisible places. The typical thickness measurement by active thermography is of the order $30-150 \mu \mathrm{m}$, depending on the substrate and coating thermal properties. However, there are other well-known widely used NDT methods, such as ultrasonic ones. But the main advantage of thermography is, that it processes images that cover certain area of the investigated material, and it allows 
analyzing the entire surface in a short time. Additionally, it is contactless method in contrast to ultrasonic one.

Let's consider 2-layer structure with the coating, having the thickness of the order $100 \mu \mathrm{m}$, as shown Fig. 5. According to the consideration above, the thermal response for ultra short pulse (Dirac) excitation for 2-layer structure is expressed as

$$
T_{\delta}(0, t)=\frac{I_{0}}{2 \sqrt{\pi} e_{1} \sqrt{t}}\left(1+2 \sum_{j=1}^{\infty}\left(\frac{e_{1}-e_{2}}{e_{1}+e_{2}}\right)^{j} e^{-\frac{j^{2} d^{2}}{a_{1} t}}\right),
$$

where: $d-$ thickness of the coating, $e_{1}, e_{2}$ - effusivities of coating and substrate respectively, $\mathrm{a}_{1}$ - coating's diffusivity, $\mathrm{t}-$ time.

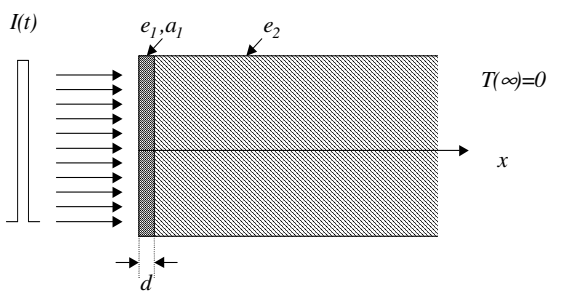

Fig.5. 2-layer structure for thin film thickness evaluation

In practice, none heat source can deliver Dirac pulse, so the real temperature response should be recalculated using the energy pulse I(t). Assuming the process of heat transfer in the sample is linear, it can be done using convolution of excitation pulse and impulse response $T_{\delta}$ as shown in eqn (5).

$$
T(0, t)=\int_{0}^{t} I(\tau) T_{\delta}(t-\tau) d \tau
$$

Temperature variation in time depends of thickness of the coating, and therefore the thermal image can be effectively used to evaluate the quality of the thin films.

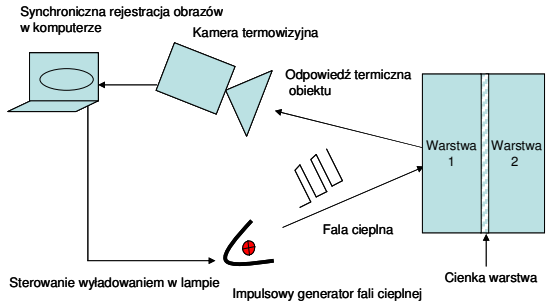

Fig.6. Concept of dynamic thermography

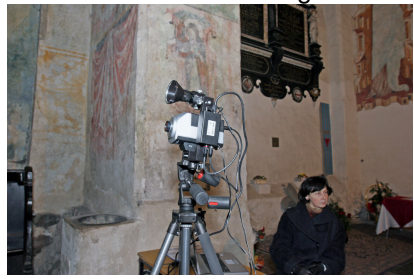

Fig. 7. Thermal system for dynamic investigation in gothic churches 


\section{http://dx.doi.org/10.21611/qirt.2006.096}

\section{Exemplary results}

As an example of thermal wave method application for architectural monuments investigations, examinations of mediaeval wall model made with materials from Castle in Malbork were performed [3]. These investigations were carried out by supplying radiating energy with frequency about $\mathrm{f}=0,1 \mathrm{~Hz}$. Exemplary thermal image is presented in Fig.8. Three hundred images registered every $\mathrm{T}=0,5 \mathrm{~s}$, where stored and processed using frequency analysis. For each point of the mage, harmonic signals where determined, including amplitude and phase (Fig. 9). Results proved that it is possible to "look" inside of a wall structure and analyze inner layers under the outer one.
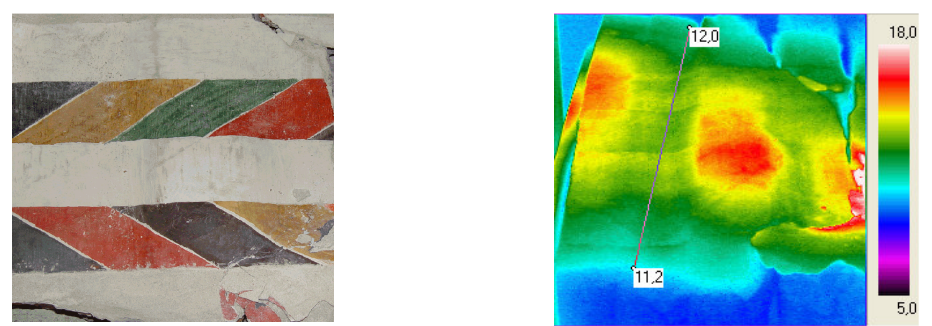

Fig. 8. Visual and single thermal frame from the sequence of 300 images

Thermal image (Fig. 8) shows horizontally oriented areas, but layers under plaster are not visible. To "see" the inert structure of the object it is necessary to carry out dynamic analysis. Phase of thermal response depends on thermal properties of the structure. In order to determine the phase of the temperature response, sequences of thermal images where tested with frequency analysis using Fourier Transformation. Amplitude spectrum as a result of this transformation for a specific point of the image is presented in Fig. 9. Dominating harmonic frequency agrees with thermal excitation frequency, although there are higher order components of the spectrum $-0,2 \mathrm{~Hz}, 0,3 \mathrm{~Hz}, \ldots$ It results from a fact that excitation was not perfectly harmonic. Results of frequency analysis are presented in Fig. 9.

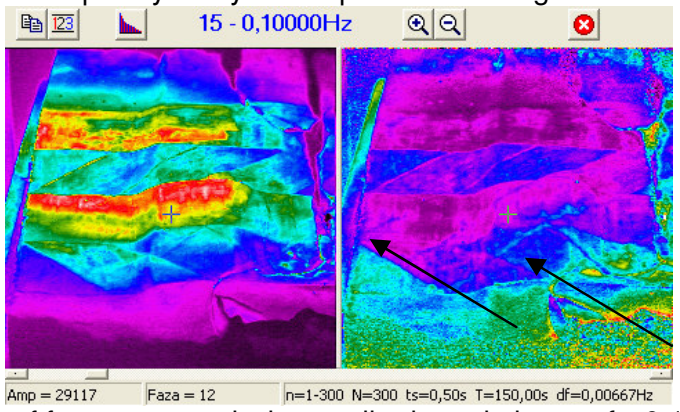

Fig. 9. Result of frequency analysis, amplitude and phase, $f=0,1 \mathrm{~Hz}, 15^{\text {th }}$ harmonic component

The best results for multilayer object can be obtained for harmonic frequency equals to excitation one. Analysis of thermal response phase distribution allows to visualize painting layers under the top one (arrows in Fig. 9). One should pay attention on the selection of appropriate excitation frequency for such non-destructive 
testing. Results of the presented work do not solve this problem. In the research, frequency $\mathrm{f}=0,1 \mathrm{~Hz}$ was arbitrary chosen. An optimal frequency of excitation signal for multilayer structures identification depends on thickness of the examined objects and their thermal parameters.

\section{Methodology of thermographic investigations in architectural monuments conservation}

In order to carry out the investigations and thermal images analysis with dynamic method it is necessary to take into account the following issues:

1. sequence of thermal images has to be captured with chosen time between each image,

2. appropriate observation time,

3. during the images registration, object is periodically thermally excited by high energy infrared lamps or convectively using blower,

4. in order to visualize layers of the structure frequency analysis should be performed.

It should be underlined that the repetition time and number of images is important for frequency analysis. For Raytheon IR2000 thermal camera, minimal repetition time equals $t_{r}=40 \mathrm{~ms}$ and can be changed up to $60 \mathrm{~s}$ (Fig. 10). When 300 images are stored, observation time equals to $\mathrm{T}_{0}=\mathrm{nt}_{\mathrm{r}}=12 \mathrm{~s}$. This time has direct influence on frequency scale resolution for spectrum components. For $T_{0}=12 \mathrm{~s}$ spectrum components has frequencies $f_{i}=\Delta f i$, where $\Delta f=1 / T_{0}=0,083 \mathrm{~Hz}$. On the basis of sampling theorem, it is known that spectrum of the signal can be analyzed for frequency $f_{s} / 2$, where $f_{s}$ is sampling frequency. For $f_{s}=1 / 40 \mathrm{~ms}$, maximum analyzed frequency is equal to $12,5 \mathrm{~Hz}$. Excitation frequency is an important aspect of the analysis. It should be selected such that at least a few periods of excitation were captured (Fig. 11).

Generally one should pursue to:

1. possibly large number of images in sequence (maximally 300 ),

2. short time of the images repetition, what depends directly on used camera,

3. integer number of thermal excitations should be observed and registered. Additionally, in order to provide appropriately large accuracy of frequency processing number of periods during observations should vary in the range 3-10.
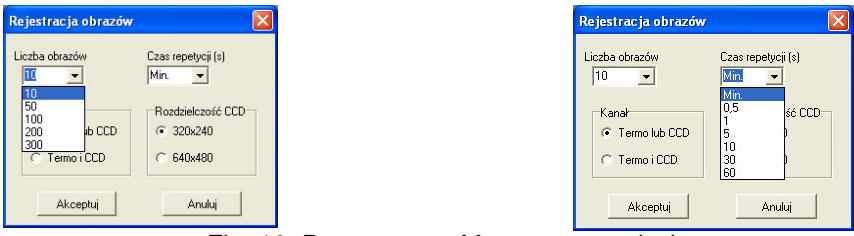

Fig. 10. Parameters of frequency analysis
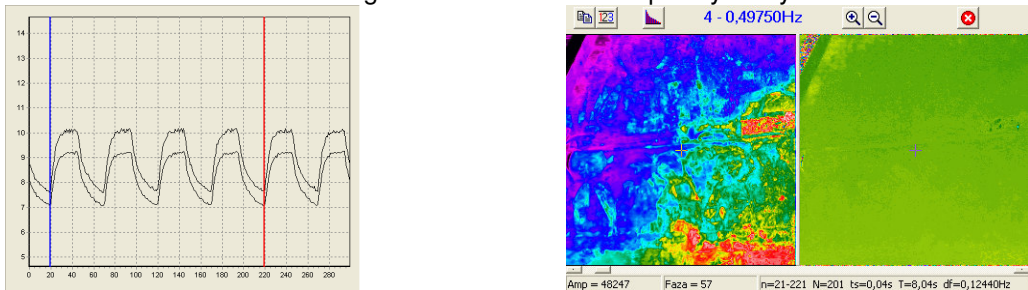

Fig. 11. Time response and results of frequency analysis 


\section{http://dx.doi.org/10.21611/qirt.2006.096}

\section{Results measurements in gothic churches}

Below, the examples of results obtained from investigations using thermography for mediaeval monuments are presented. Walls, frescos, plasters and paintings were considered (Fig. 12-19).

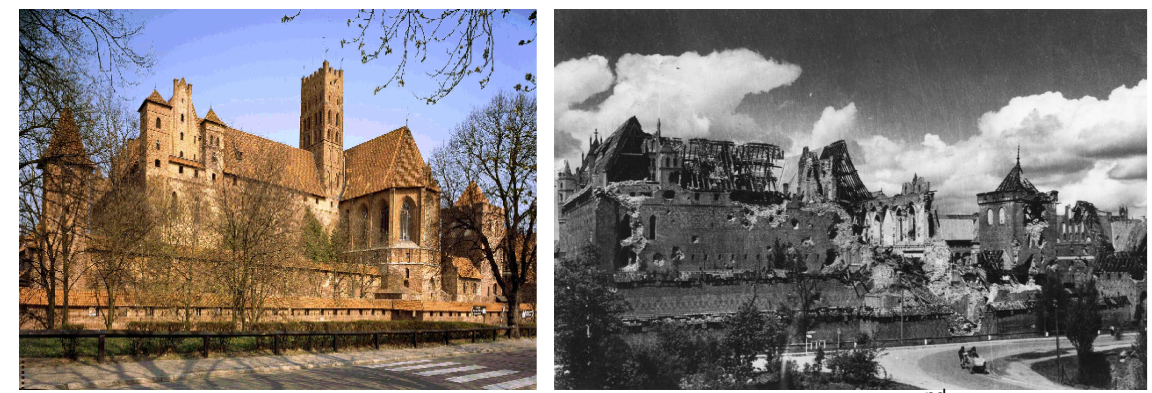

Fig. 12. Castle in Malbork, actual state and distortion after the $2^{\text {nd }}$ World War phot. Leszek Okoński and Archive of MZM
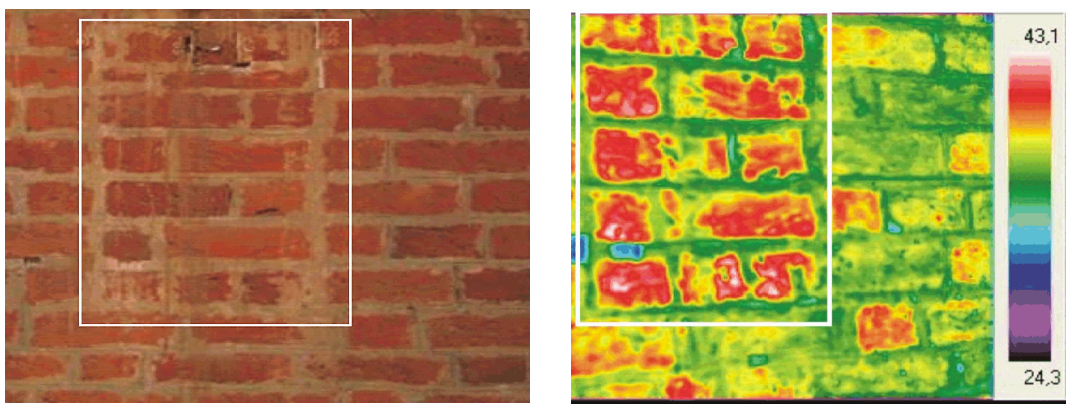

Fig. 13. Rebricklaying in infrared radiation, church of Lady Mary in Malbork Castle
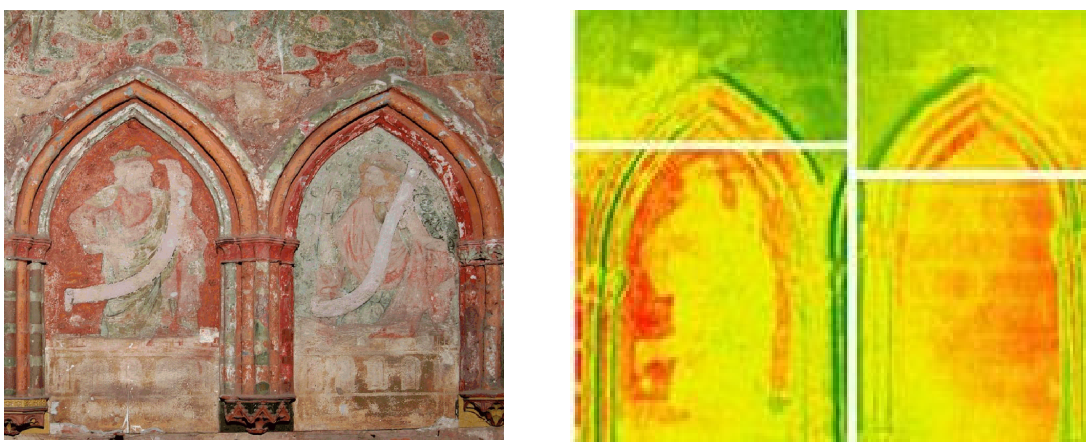

Fig. 14. Fragment of framing in church of Lady Mary in Malbork Castle, bricks layout visible under post-mediaeval plaster without original polychrome 

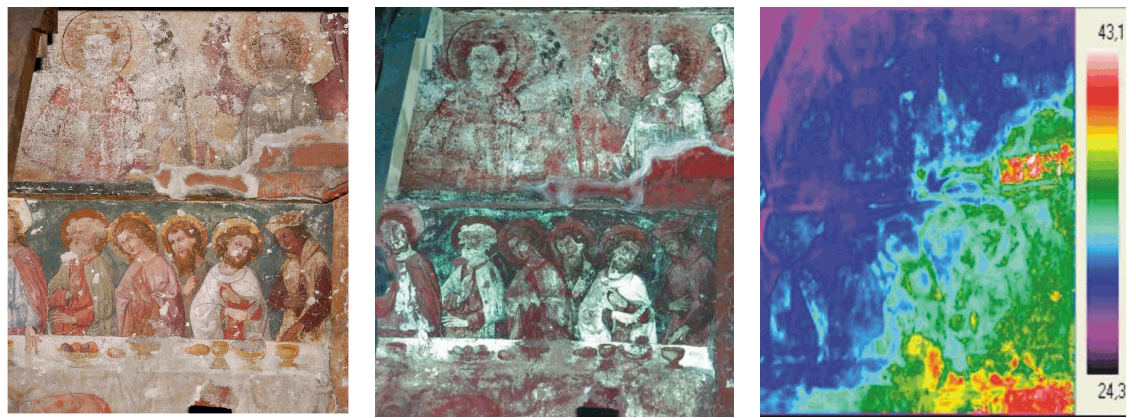

Fig. 15. Fragment of gothic painting in church of Lady Mary in Malbork Castle, visible, UV and IR images, distortion visible

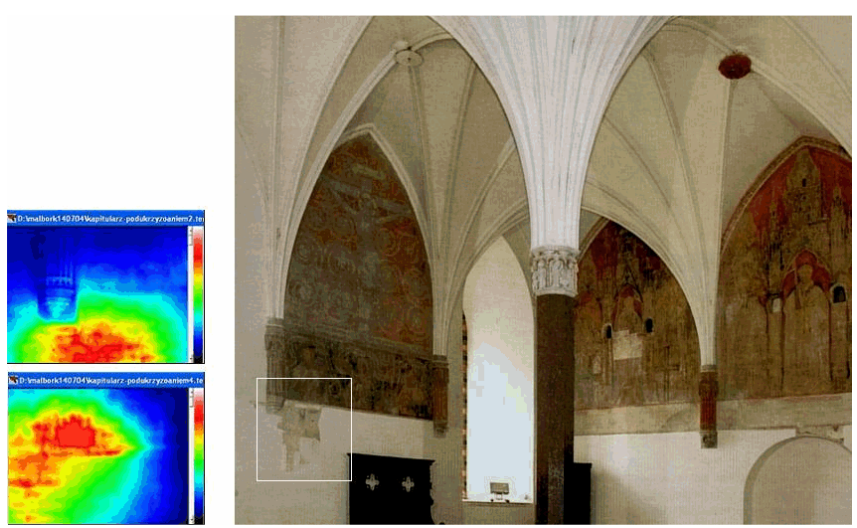

Fig. 16. Chapter room, thermal images show the invisible structure under the gothic plaster and polychrome

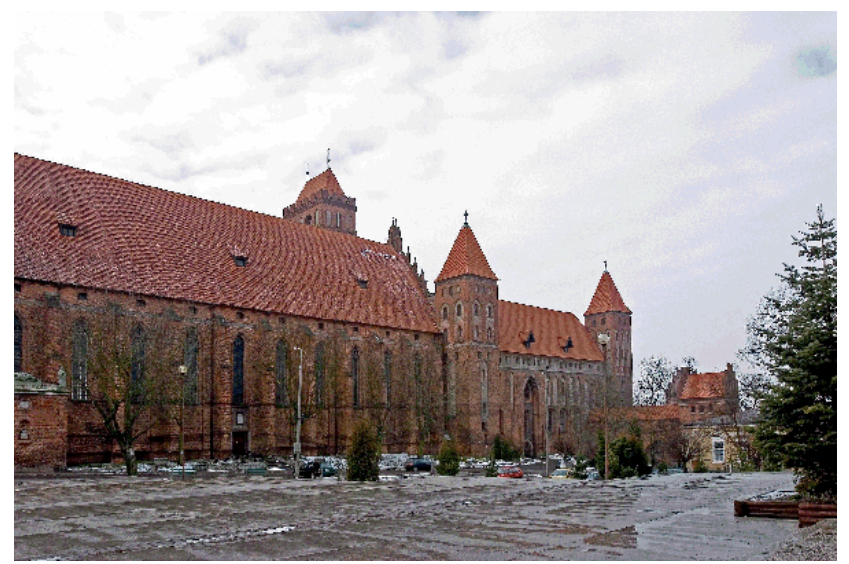

Fig. 17. Convent castle in Kwidzyn, in castle church, a series of XVI century paintings on unknown theme, phot. A.Skowroński 

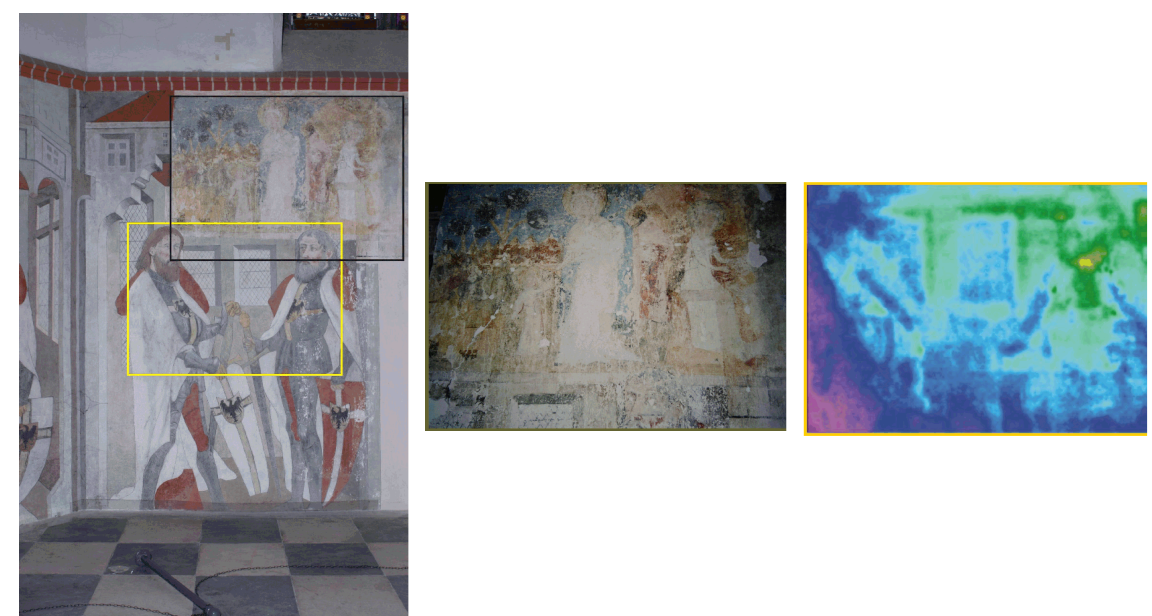

Fig. 18. Opened mediaeval fresco newer under newer repaintings in church in Kwidzyn, thermal image shows the distortions of XVI-century paintings and gaps in plaster

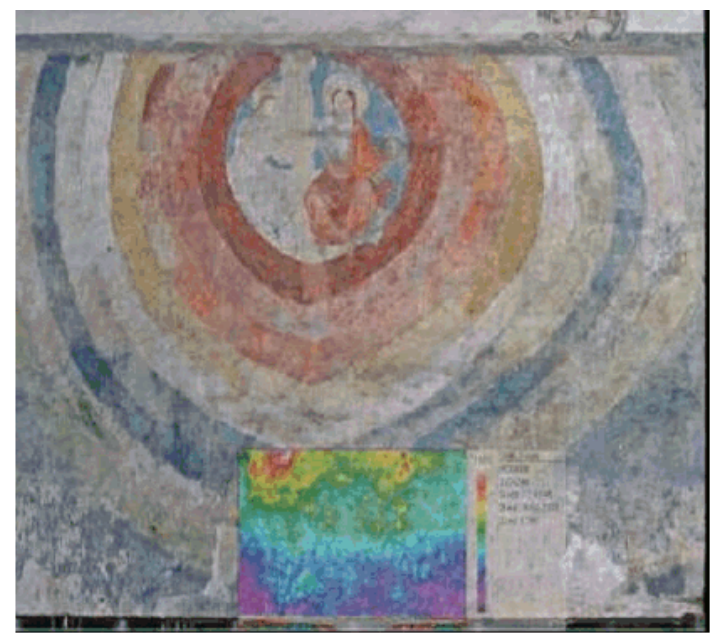

Fig. 19. Gothic painting in church of Lady Mary in Torun, thermal image show the distortion of bottom part of the painting, paraffin and soot from the candles being lighted for years

\section{Conclusions}

Thermography is often applied in many different fields. First attempts to use it for architectural monuments conservation were made lately. Passive and dynamic 
thermography is very helpful in investigations of works of art and architectural monuments. Although method is not fully developed, first results are optimistic. Examined structure can be penetrated with a thermal wave on small depth. Shape of bricks under the plaster can be visualized without special problems. Material form different periods can be differentiated. Future works on improvement of thermographic methods for architectural monuments will certainly continue. It can be predicted that in the near future investigations with convective excitation will be undertaken as well. Spectral analysis for chosen infrared radiation wavelengths should be considered. Thermal cameras for short infrared $(1-2 \mu \mathrm{m})$ will be tested in conservation applications. There is still a problem to choose excitation frequency for dynamic thermography, that the deepness of thermal wave penetration and sensitivity ware satisfactory.

\section{REFERENCES}

[1] Accardo G., Camuffo D., Ferrari G., A micrometeorological study of the air inside the Scrovegni Chapel in Padua [in:] Deterioramento e Conservatione della Pietra, 3 Congresso Int., Venezia 1979, s.665-676.

[2] Accardo G. and Fassina V., On the Deterioration of the 11 th and 12 th Century Mosaics of the Basilica of Torcello: Proposal of a non Destructive Test to Evaluate the Moisture of a Wall, Progress report 81/15/9-11, Venezia 1981.

[3] High Castle of Malbork. Interdisciplinary Research of the Northern Wing, ed. by M. Poksińska, Toruń 2006.

[4] Krapez J.C. Compared performances of four algorithms used for modulation thermography, Proc. of the Eurotherm Seminar 60 "Quantitative Infrared Thermography-QIRT'98", Sep.7-10, 1998, Łódź, Poland, p. 148-153.

[5] Maldague X., Marinetti S. Pulse phase infrared thermography. J. Appl. Phys., 79.

[6] Vavilov V., Marinetti S., Grinzato E., Bison P. Thermal tomography, characterisation and pulse phase thermography of impact damage in CFRP, or why end-users are still reluctant about practical use of transient IR thermography. Snell (J.R.) and Wurzbach (R.N.) eds., Thermosense-XX, SPIE Proc. 3361, 1998, p.275-281.

[7] Vavilov V., Maldague X., Picard J. et al. Dynamic thermal tomography: new NDE technique to reconstruct inner solids structure using multiple IR image processing. Thompson (D.O.) and Chimenti (D.E.) eds., Rev. of Progress in Quant. NDE, vol.11, Plenum Press, New York, 1992, p.425-432.

[8] Wu D., Salerno A., Schönbach B., Halin H., Busse G. Phase-sensitive modulation thermography and its applications for NDE. Wurzbach (R.N.) and Burleigh (D.D.) eds., Thermosense-XIX, SPIE Proc. 3056, 1997, p.176-183.

[9] Vavilov V., Marinetti S., Grinzato E., Bison P. Thermal tomography, characterisation and pulse phase thermography of impact damage in CFRP, or why end-users are still reluctant about practical use of transient IR thermography. Snell (J.R.) and Wurzbach (R.N.) eds., Thermosense-XX, SPIE Proc. 3361, 1998, p.275-281.

[10] Vavilov V., Almond D. P., Busse G., Grinzato E., Krapez J.C., Maldague X., Marinetti S., Peng W., Shirayev V., Wu D. Infrared thermographic detection and characterisation of impact damage in carbon fibre composites: results of the round robin test, Proc. of the Eurotherm Seminar 60 "Quantitative Infrared Thermography-QIRT'98", Sep.7-10, 1998, Łódź, Poland, p. 43-52. 